Supporting Information

\title{
Low-temperature Formation of Nitrous Oxide from Dinitrogen, Mediated by Supported Tungsten Nanoclusters**
}

\author{
Wataru Yamaguchi and Junichi Murakami*
}

\section{Deposition and fixation of size-selected W clusters on a graphite surface}

$\mathrm{W}_{n}^{+}$cluster ions $(n=2-6)$, generated by sputtering $\mathrm{W}$ plates with high-energy $\mathrm{Xe}^{+}$ion beams, were size-selected by a quadrupole mass-filter, cooled by collision with helium gas, and deposited on an HOPG surface at room temperature. By our experimental setup, incident energies of the cluster ions to the surface can be reduced to less than $\sim 0.3$ eV/cluster. ${ }^{[\mathrm{S} 1]}$ Since $\mathrm{W}-\mathrm{W}$ bond energy (e. g., $\sim 5 \mathrm{eV}$ for $\mathrm{W}_{2}$ ) is larger by an order of magnitude than the incident energy, it is ensured that the clusters are non-destructively deposited, or, "soft land" on the surface. Prior to the cluster deposition, the HOPG surface was bombarded by $\mathrm{Ar}^{+}$ion with a collision energy of $50 \mathrm{eV}$ to create defects on its outermost surface that work as pinning centers for anchoring the clusters separately. ${ }^{[\mathrm{S} 2]}$

\section{TDS measurement}

For TDS, the substrate was heated with a constant temperature rise of $0.5 \mathrm{~K} / \mathrm{sec}$ by electron bombardment using a tungsten filament located at the back of the substrate. The substrate temperature was monitored by using an alumel-chromel thermocouple. Desorbed species were analyzed by a quadrupole mass spectrometer.

\section{Purity of $\mathrm{N}_{2}$ gas used for the experiments}

If the $\mathrm{N}_{2} \mathrm{O}$ desorption is due to impurities such as $\mathrm{N}_{2} \mathrm{O}$ or $\mathrm{NO},{ }^{[\mathrm{S} 3]}$ which might exist in the $\mathrm{N}_{2}$ gas, the desorption should be observed also for dry $\mathrm{N}_{2}$. Indeed, when $\mathrm{W}_{5}$ was exposed to dry $\mathrm{N}_{2} \mathrm{O}$ or $\mathrm{NO}$ gas at $140 \mathrm{~K}$, desorption of $\mathrm{N}_{2} \mathrm{O}$ was observed in both cases. This in turn indicates that the 
${ }^{15} \mathrm{~N}_{2}$ gas used in the present experiment is free from such impurities. This is consistent with mass spectroscopic analysis which showed no sign of impurities like $\mathrm{N}_{2} \mathrm{O}, \mathrm{NO}$ or $\mathrm{NO}_{2}$ in the $\mathrm{N}_{2}$ gas.

\section{DFT calculation}

The geometry optimizations were carried out by a DFT method using the B3LYP hybrid functional. The LANL2DZ and the 6-311+G(d) basis set were employed for $\mathrm{W}$ and $\mathrm{N}$ atoms, respectively. Calculations were performed using the Gaussian 03 code. $^{[\mathrm{S} 4]}$

For the $\mathrm{N}_{2}$-adsorbed $\mathrm{W}_{n}$, strictly speaking, one cannot calculate the vibrational frequency of $\mathrm{N}_{2}$ ignoring the underlying $\mathrm{W}_{n}$. The frequencies given in the present article are, in fact, the highest eigenfrequencies among those of all the vibrational modes of $\mathrm{N}_{2} \mathrm{~W}_{n}$, the whole system of $\mathrm{N}_{2}-\mathrm{W}_{n}$ complexes. The frequencies can, however, be virtually regarded as the N-N stretching mode frequencies, i. e., the frequencies of the vibrational modes in which $\mathrm{W}$ atoms almost stand still and only two $\mathrm{N}$ atoms vibrate in anti-phase. This is because the mass of an $\mathrm{N}$ atom is an order of magnitude smaller than that of a $\mathrm{W}$ atom and the frequencies in question are always fairly larger than those of modes involving motions of the $\mathrm{W}$ atoms.

We have also calculated the geometrical structure of $\mathrm{W}_{5}$ on a graphen surface, and found that the structure remains almost the same as the isolated cluster structure. This suggests $\mathrm{N}_{2}$ adsorption geometry on the isolated and the supported cluster is similar to each other. The calculations of the $\mathrm{N}_{2}$ adsoption on isolated clusters, therefore, should give an insight into that on the supported clusters.

\section{References}

[S1] W. Yamaguchi, K. Yoshimura, Y. Maruyama, K. Igarashi, S. Tanemura, J. Murakami, Chem. Phys. Lett. 1999, 311, 415-420.

[S2] V. Vijayakrishnan, C. N. R. Rao, Surf. Sci. 1991, 255, L516-L522.

[S3] W. A. Brown, D. A. King, J. Phys. Chem. B 2000, 104, 2578-2595.

[S4] M. J. Frisch et al., Gaussian 03 Revision D.01, Gaussian, Inc., 
Wallingford, CT, 2004. 